\title{
Background Strain and Natural Selection Improves Survival of HIBM Murine Model
}

\author{
Valles-Ayoub. $Y^{1,2, *}$, Khokher. $Z^{1,3}$, Sandoval. L 1,3, Haghighatgoo. $\mathbf{A}^{1,2}$, No. $\mathbf{D}^{1,3}$, Saechao. $C^{1}$, Garcia-Figueroa. $\mathbf{J}^{1,3}$, Carbajo. $\mathbf{R}^{1,3}$, Darvish. $\mathbf{B}^{2}$ \\ and Darvish. $\mathrm{D}^{1,2}$
}

${ }^{1}$ HIBM Research Group, Reseda, CA, USA

2VA Greater Los Angeles (VA-GLA/UCLA), Los Angeles, CA, USA

${ }^{3}$ Los Angeles Mission College, Sylmar CA, USA

\begin{abstract}
GNE myopathy, or Hereditary Inclusion Body Myopathy (HIBM), is an autosomal recessive adult-onset muscle wasting disorder caused by hypomorphic GNE (UDP-N-acetylglucosamine 2-epimerase/N-acetylmannosamine kinase), the rate-limiting enzyme of sialic acid (Sia) biosynthesis. Unlike human patients, mice bearing the Gne ${ }^{\text {M712T/M712T }}$ genotype in C57BL/6 background strain suffer severe glomerular hematuria, show incomplete podocyte development, and do not survive beyond the first few days of life. We crossed heterozygous mice (Gne ${ }^{\mathrm{M712T/} /}$ ) of $\mathrm{B} 6$ strain with FVB strain mice. In mixed inbred FVB; B6 background, the homozygous mice showed attenuated glomerular disease and survived longer (mean survival $23.48 \pm 13.99$ weeks, $n=73$ ). Within the first 2 generations, $26 \%$ of the homozygous mice survived past the age of 40 weeks, and within the subsequent 3 generations the frequency of homozygous mice surviving past age of 40 weeks had increased to $44 \%$. Additionally, the homozygous mice (Gne ${ }^{\mathrm{M} 712 \mathrm{tM} 712 \mathrm{t})}$ living past the age of 42 weeks began to show muscle pathology. These findings suggest that the mouse background strain affects the disease phenotype, and that natural selection may have an influence on the long-term maintenance of mouse models of human disease.
\end{abstract}

Keywords: Muscular dystrophy; Nonaka; Distal Myopathy with Rimmed Vacuoles (DMRV); Hereditary Inclusion Body Myopathy (HIBM); Sialylation; Glycosylation; GNE myopathy

\section{Introduction}

Inclusion Body Myositis and Myopathies (IBMs) comprise a group of adult-onset slowly progressive muscle disorders that typically result in severe disability [1]. Hereditary Inclusion Body Myopathy (HIBM), also called Inclusion Body Myopathy Type 2 (IBM2, MIM: 600737), is the most common inherited form of IBMs. HIBM is an autosomal recessive adult-onset muscle wasting disorder caused by mutations in the GNE gene (MIM: 603824) [2-4]. GNE encodes for the bifunctional enzyme UDP-N-acetylglucosamine 2-epimerase/Nacetylmannosamine kinase (GNE/MNK), and is the rate-limiting enzyme of sialic acid (Sia) biosynthesis. GNE mutations encoding for hypomorphic GNE/MNK enzyme have been associated with the pathophysiology of skeletal muscle in several clinical studies in patients with HIBM $[5,6]$. Although several GNE mutations can lead to HIBM and related heritable myopathies, muscle wasting and weakness are the characteristic symptoms and often the only debilitating manifestation in HIBM. To date, two mouse models have been generated for preclinical studies on HIBM: 1) the Gne ${ }^{\mathrm{M} 712 \mathrm{~T}}$ knock-in mouse model expressing the mutation p.M712T, the most common founder genotype of patients with HIBM; and 2) transgenic mice bearing the human GNE with the p.D176V mutation in GNE-null background $[7,8]$-Transgenic mice expressing the human GNE with p.D176V mutation show myopathy after the age of 40 weeks that resembles HIBM in human patients [8]. The Gne $e^{\mathrm{M} 712 \mathrm{~T}}$ murine model is produced by homologous recombination, but the phenotype varies depending on the mouse strain [7]. In the C57BL/6 mouse strain, Gne ${ }^{\mathrm{M} 712 \mathrm{~T} / \mathrm{M} 712 \mathrm{~T}}$ mice develop severe kidney disease, glomerular hematuria, hyposialylation of podocalyxin, and partial formation of podocyte foot processes in the glomerular filtration barrier. Consequently, Gne $\mathrm{M}^{\mathrm{M} 12 \mathrm{~T} / \mathrm{M} 712 \mathrm{~T}} \mathrm{C} 57 \mathrm{BL} / 6$ mice fail to survive beyond the first three postnatal days of life [7].

To produce a mouse that lives long enough to serve as a viable animal model for HIBM caused by GNE expressing p.M712T, we needed a novel hybrid mouse that expressed this mutation but did not cause the renal impairment found in $\mathrm{Gne}^{\mathrm{M} 712 \mathrm{~T} / \mathrm{M} 712 \mathrm{~T}} \mathrm{C} 57 \mathrm{BL} / 6$. In this study, we selected the FVB background mouse strain for cross-breeding because FVB mice display vigorous reproductive function as evidenced by their large litter size [9]. In addition, FVB/NJ mice often exhibit a modified genetic disease phenotype compared to B6 animals [10-12]. By back-crossing two generations of mixed inbred mice, we generated a viable animal model for evaluating the effects of the $\mathrm{Gne}^{\mathrm{M} 712 \mathrm{~T}}$ mutation on disease phenotype in different inbred mouse strains.

Multiple GNE gene point mutations have been observed in patients diagnosed with either HIBM or distal myopathy with rimmed vacuoles (DMRV). Although GNE point mutations appear to alter Sia acid biosynthesis, these mutations may trigger different diseases in mice than in humans. In a recent study, Ito et al. produced mice with a V572L point mutation in the GNE kinase domain to create a mouse model of DMRV/HIBM [13]. The Gne ${ }^{\mathrm{V} 572 \mathrm{~L}}$ mutant mice had a short lifespan and showed renal disorders, including abnormal podocyte foot process morphologies in the kidneys. However, as in the case of the knock-in mouse carrying the $\mathrm{Gne}^{\mathrm{M} 712 \mathrm{~T}}$ point-mutation, homozygous mice bearing the $\mathrm{Gn} \mathrm{e}^{\mathrm{V} 572 \mathrm{~L}}$ point-mutation exhibited no myopathies or motor dysfunction. In addition, $\mathrm{Gn} \mathrm{e}^{\mathrm{V} 572 \mathrm{~L}}$ mutant mice had a much longer lifespan compared to the Gne $\mathrm{M}^{\mathrm{M} 712 \mathrm{~T}}$ mutant mouse model. Renal disorders were more severe in mice with the Gne ${ }^{\mathrm{M} 712 \mathrm{~T}}$ pointmutation in comparison to those with the $\mathrm{Gne}^{\mathrm{V} 572 \mathrm{~L}}$ point-mutation [13]. In the third model of a GNE-mutant mouse with the transgenic model expressing the human GNE gene with D176V point-mutation

*Corresponding author: Dr. Yadira Valles-Ayoub, M.D., PhD, Director of Research, HIBM Research Group18341 Sherman Way, \#201A, Reseda, CA, USA Tel: +91 818 789-1033; E-mail: yadira@hibm.org

Received October 30, 2012; Accepted November 19, 2012; Published November 21, 2012

Citation: Valles-Ayoub Y, Khokher Z, Sandoval L, Haghighatgoo A, No D, et al (2013) Background Strain and Natural Selection Improves Survival of HIBM Murine Model. Mol Biol 2:109. doi:10.4172/2168-9547.1000109

Copyright: $\odot 2013$ Valles-Ayoub Y, et al. This is an open-access article distributed under the terms of the Creative Commons Attribution License, which permits unrestricted use, distribution, and reproduction in any medium, provided the original author and source are credited. 
mentioned previously, the mice displayed myopathic features, but exhibited no renal impairment [8].

The $\mathrm{Gne} \mathrm{M}^{\mathrm{M} 72 \mathrm{~T}}$ and $\mathrm{Gne} \mathrm{V}^{\mathrm{V} 72 \mathrm{~L}}$ mouse models appear to have varying severity. While the V572L mutation may affect kinase domain dimerization, the M712T mutation may alter the GNE structure, thereby disrupting ATP catalysis, carbohydrate binding, and phosphoryl transfer [14]. These changes in turn may influence the degree of hyposialylation of glycoproteins and glycolipids including podocalyxin (PC).

\section{Method}

\section{Animals}

FVB/NJ mice were obtained from Jackson Laboratories, and a $\mathrm{Gne}^{\mathrm{M} 712 \mathrm{~T}}$ mouse was provided by HIBM Research Group [7]. Breeding between these two parental strains and between the inbred hybrids progeny was performed at the VA Greater Los Angeles Healthcare System, Veterinary Medical Unit. The mice had access ad libitum to water and either Mouse Diet 5015 chow (PMI Nutrition International, LLC, and Brentwood, MO) or Teklad Rodent Diet (Harlan Laboratories, Indianapolis, IN). Studies were conducted in accordance with the guidelines set forth by the VA Greater Los Angeles Healthcare System Institutional Animal Care and Use Committee and by the National Institute of Health (NIH) Guidelines for the Care and Use of laboratory animals.

\section{Specimen}

Mouse tail snips that were approximately $5 \mathrm{~mm}$ in length were procured and stored at $20^{\circ} \mathrm{C}$ in $1.5 \mathrm{~mL}$. micro centrifuge tubes. Kidneys were preserved using formalin. Muscle tissue was preserved using a snap-freeze technique with methyl butane.

\section{Nucleic acid isolation}

Mouse tail was lysed using regular alkaline lysis buffer with $5 \mu \mathrm{L}$ of proteinase $\mathrm{K} 20 \mathrm{U} / \mu \mathrm{L}$, followed by ethanol precipitation. The pellet was resuspended in $\mathrm{H}_{2} \mathrm{O}$. DNA optical density of this solution was measured with the ND-1000 spectrophotometer.

\section{Gne $^{\mathrm{M} 712 \mathrm{~T}}$ genotype}

Genotype was done following the melting curve analysis [15].

\section{Tissue staining}

Kidney tissues were analyzed and stained with Hematoxylin and Eosin ( $\mathrm{H}$ and $\mathrm{E})$. Muscle morphology was analyzed by $\mathrm{H}$ and $\mathrm{E}$ and Gomori Trichrome (GT).

\section{Results}

We produced mice bearing the most common mutation observed in HIBM/DMRV patients, the Middle East founder GNE: p.M712T (atg>acg) allele, in mixed inbred B6; FVB background. We previously reported that the number of homozygous mice in our mixed inbred strain surviving to weaning age was far below the Mendelian expected rate of $25 \%$ from heterozygous-heterozygous matings [15]. In the current study the survival of homozygotes after the weaning age was only $6 \%$. Within the first 2 generations, $26 \%$ of the homozygous mice survived past the age of 40 weeks. Within the subsequent 3 generations the frequency of homozygous mice surviving past the age of 40 weeks had increased dramatically to $44 \%$ (Figure 1).

The homozygous mice showed normal kidney morphology, with kidney cortex and capsules exhibiting no visible abnormalities. The gross anatomy of the kidneys appeared normal compared with our previous findings as depicted in (Figure 2). Homozygous mice

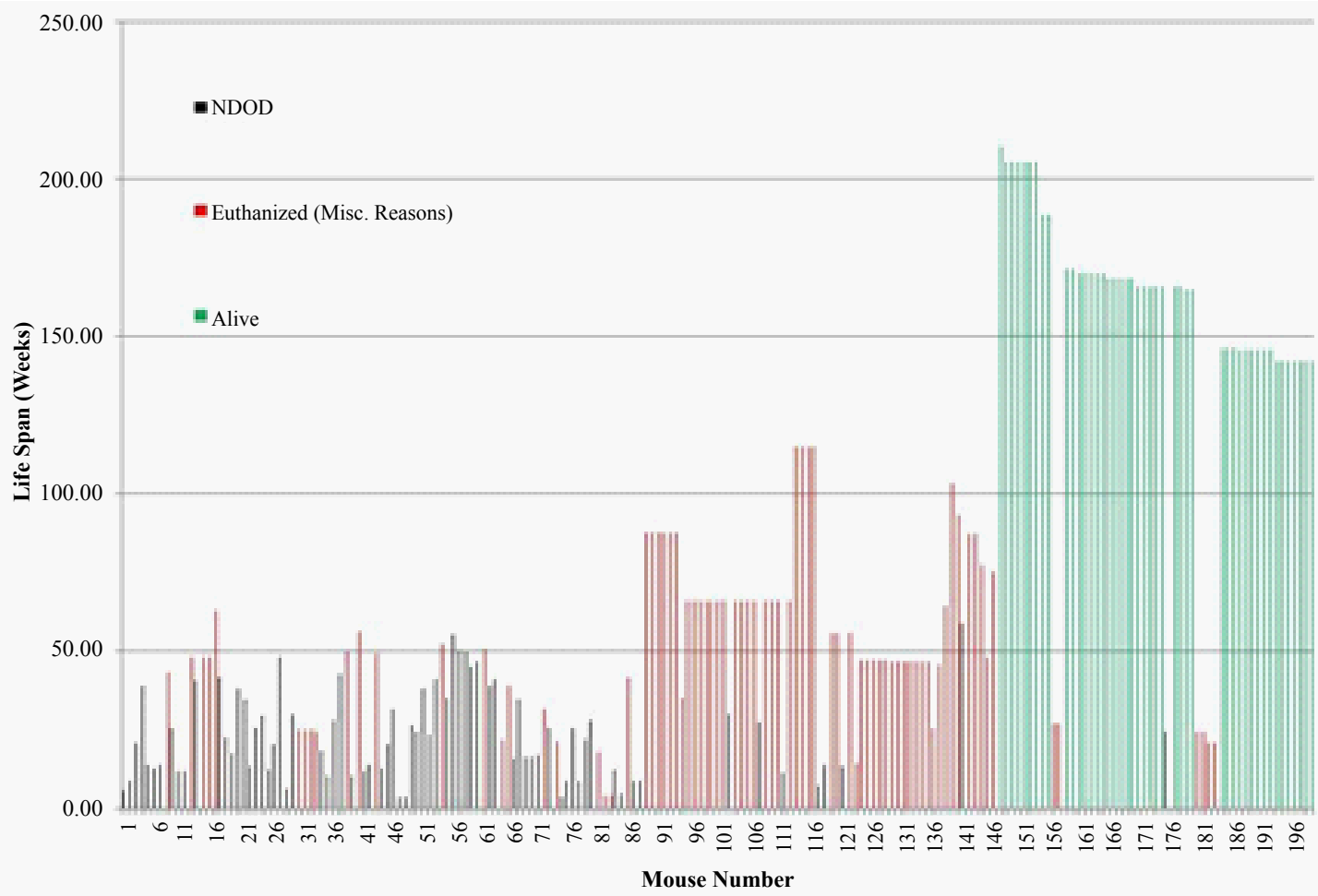

Figure 1: Black bars indicate mice died naturally. Red bars indicate mice were euthanized. After mouse \#87, mice survival are $>40 w k s$. Green bars indicate mice are currently alive. 
$\left(\mathrm{Gne} \mathrm{M}^{\mathrm{M} 712 \mathrm{~T} / \mathrm{M} 712 \mathrm{~T}}\right)$ living past the age of 42 weeks began to show muscle pathology, as confirmed by muscle staining with $\mathrm{H}$ and $\mathrm{E}$, Gomori Trichrome (Figure 3). In mice with the homozygous genotype, muscle sections clearly indicated variation in muscle fibre size, internalized nuclei in scatter fibres and small angular fibres, and also revealed the presence of cytoplasmic inclusions. No fibrosis, necrotic, or regenerating processes was noted. Gomori Trichrome stained vacuoles were rimmed by eosinophillic granules.

\section{Discussion}

Allelic heterogeneity of the GNE gene has been reported in human studies, with many mutations in this gene identified in people with IBM2 [3]. GNE mutations associated with IBM2 have been detected in either the epimerase or the kinase domain of the enzyme. These mutations lead to decreased production of Sia $[5,6]$. By contrast, several mutations in the allosteric site of the GNE gene involved in the normal regulation of the enzyme result in the overproduction of Sia that leads to sialuria [16].

In this study the disease phenotype severity varied among the

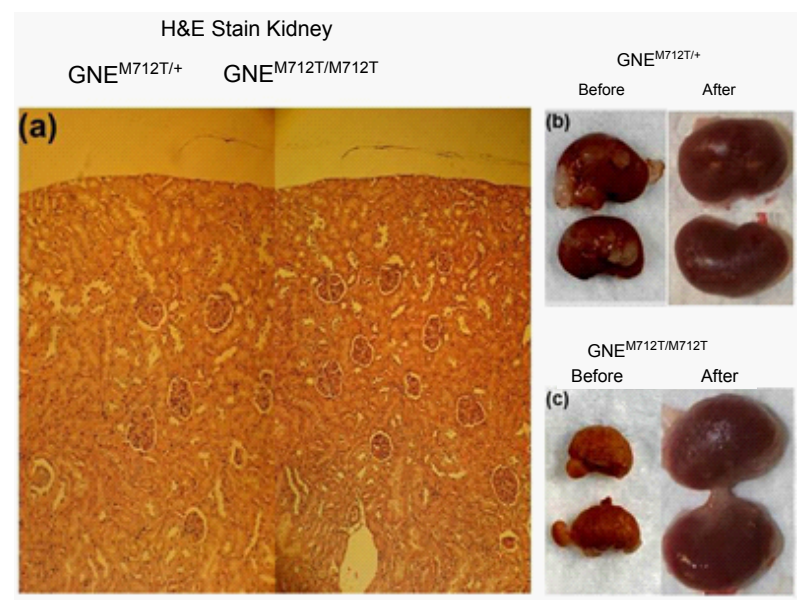

Figure 2: (a): Kidney H\&E Stain Heterozygous compared to homozygous. (b), (c): Clear difference on gross anatomy between kidneys procured on $1^{\text {st }}$ and $3^{\text {rd }}$ generation of heterozygous and homozygous.

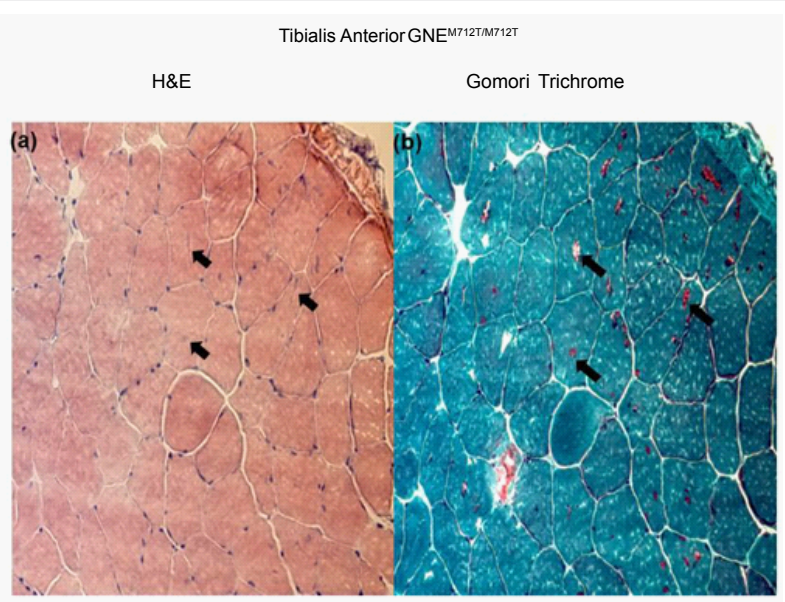

Figure 3: Light micrographs of tibialis anterior muscle cross section showing structural pathology found in homozygous mice (GNE ${ }^{\mathrm{M} 712 \mathrm{~T} / \mathrm{M} 712 \mathrm{~T}}$ ) living past the age of 42 weeks. Arrows indicate cytoplasmic inclusions (a) Haematoxylin and Eosin $\times 10$ (b) Gomori Trichrome $\times 10$. mixed inbred mouse strains produced by first and second generation inbreeding. The most interesting observation was the association between the background mouse strain and severity of renal disease caused by the Gne $\mathrm{M}^{\mathrm{M} 712 \mathrm{~T} / \mathrm{M} 712 \mathrm{~T}}$ genotype. Since there are no reports of either renal pathology or overt kidney disease in human patients genotyped for $\mathrm{Gne}^{\mathrm{M} 712 \mathrm{~T} / \mathrm{M} 712 \mathrm{~T}}$, the reason for renal disorders in the homozygous mice suggests that the efficiency of the sialic biosynthetic pathway in different organs is influenced by other background genes. In a related preclinical investigation, high serum Sia levels paradoxically were present in the same mouse model used in our study, which is probably caused by renal insufficiency. Higher serum Sia levels possibly have a protective effect on the myofibers of this mixed inbred mouse model and thus may contribute to the delayed onset of myopathy in mice bearing $\mathrm{Gne}^{\mathrm{M} 712 \mathrm{~T} / \mathrm{M} 712 \mathrm{~T}}[17]$.

The goal of our experiments involving FVB; B6 mixed inbred background strains of the Gne $\mathrm{e}^{\mathrm{M} 712 \mathrm{~T} / \mathrm{M} 712 \mathrm{~T}}$ mouse model is ultimately to produce a mouse with reduced renal phenotype and possibly HIBMlike pathology seen in skeletal muscles. This animal disease model would bear closer genotypic similarity to HIBM in humans than transgenic models, thus providing researchers with an in vivo tool for investigating the pathogenesis underlying GNE: p.M712T linked HIBM as well as testing of potential treatments. As noted previously, mice expressing Gne $\mathrm{M}^{\mathrm{M} 72 \mathrm{~T} / \mathrm{M} 712 \mathrm{~T}}$ survive for only a few days after birth. Yet in the present study we unexpectedly found that VB; B6 mixed inbred background strains attenuate kidney disease in the $\mathrm{Gne}^{\mathrm{M} 712 \mathrm{~T} /}$ ${ }^{\mathrm{M} 712 \mathrm{~T}}$ mouse.

Even more surprising was the discovery that maintenance (i.e., post-weaning survival) of the long-term mouse colony increased incrementally over 5 generations, and therefore appeared to be influenced by natural selection. Mice showing the least amount of renal pathology were favoured for longer-term survival. Kidney disease detected in the Gne $\mathrm{M}^{\mathrm{M} 712 \mathrm{~T} / \mathrm{M} 712 \mathrm{~T}}$ mouse model produced from two distinct strains was significantly reduced over 5 generations. Additionally, HIBM-like muscle pathology was evident in mice surviving beyond 42 weeks of age.

Various polymorphisms not yet delineated in our mixed inbred mouse model may reflect earlier effects of natural selection on the two reproductively separate parental mouse strains. In our study the phenotypic variation associated with the generation-to-generation increases in the rate of post-weaning survival may be an outcome of positive micro selection that serves to maximize the survival rate of the mouse colony population. On the other hand, a change in allele frequencies leading to a modified phenotype may have resulted from negative selection against one or more deleterious mutations causing renal impairment.

\section{Conclusion}

As indicated in other published reports, our findings reveal that the background strain of a mouse model can significantly affect the phenotype of a particular disease $[18,19]$. Neither the presence nor absence of natural selection as the driving force behind the prolonged post-weaning survival of the mice can be confirmed conclusively based on the available evidence. Future studies are needed to determine if the increased lifespan of successive generations of $\mathrm{Gne}^{\mathrm{M} 712 \mathrm{~T}}$ mutant mice observed in this investigation was due to natural selection.

The increase in the survival rate of the mice was statistically significant and, regardless of the cause of this increase, may hold practical benefit for future preclinical research on heritable 
Citation: Valles-Ayoub Y, Khokher Z, Sandoval L, Haghighatgoo A, No D, et al. (2013) Background Strain and Natural Selection Improves Survival of HIBM Murine Model. Mol Biol 2:109. doi:10.4172/2168-9547.1000109

myopathies. Production of mouse models of various types of human disease in several inbred background strains eventually could lead to the development of an optimal disease mouse model that resembles HIBM in human patients.

\section{Acknowledgment}

For making this work possible, we extend gratitude to the following:

Advancement of Research for Myopathies (A.R.M) for funding.

Dr. Melissa Lucas and Jennifer Kay for mouse colony management.

\section{References}

1. Needham M, Mastaglia FL, Garlepp MJ (2007) Genetics of inclusion-body myositis. Muscle Nerve 35: 549-561.

2. Eisenberg I, Avidan N, Potikha T, Hochner H, Chen M, et al. (2001) The UDP-Nacetylglucosamine 2-epimerase/ $\mathrm{N}$-acetylmannosamine kinase gene is mutated in recessive hereditary inclusion body myopathy. Nat Genet 29: 83-87.

3. Darvish D, Vahedifar P, Huo Y (2002) Four novel mutations associated with autosomal recessive inclusion body myopathy (MIM: 600737). Mol Genet Metab 77: 252-256.

4. Nishino I, Noguchi S, Murayama K, Driss A, Sugie K, et al. (2002) Distal myopathy with rimmed vacuoles is allelic to hereditary inclusion body myopathy. Neurology 59: 1689-1693.

5. Noguchi S, Keira Y, Murayama K, Ogawa M, Fujita M, et al. (2004) Reduction of UDP-N-acetylglucosamine 2-epimerase/ $\mathrm{N}$-acetylmannosamine kinase activity and sialylation in distal myopathy with rimmed vacuoles. J Biol Chem 279: 11402-11407.

6. Sparks SE, Ciccone C, Lalor M, Orvisky E, Klootwijk R, et al. (2005) Use of a cell-free system to determine UDP-N-acetylglucosamine 2-epimerase and $\mathrm{N}$-acetylmannosamine kinase activities in human hereditary inclusion body myopathy. Glycobiology 15: 1102-1110.

7. Galeano B, Klootwijk R, Manoli I, Sun M, Ciccone C, et al. (2007) Mutation in the key enzyme of sialic acid biosynthesis causes severe glomerular proteinuria and is rescued by N-acetylmannosamine. J Clin Invest 117: 1585-1594.

8. Malicdan MC, Noguchi S, Nonaka I, Hayashi YK, Nishino I (2007) A Gne knockout mouse expressing human V572L mutation develops features similar to distal myopathy with rimmed vacuoles or hereditary inclusion body myopathy Hum Mol Genet 16:115-128.

9. Taketo M, Schroeder AC, Mobraaten LE, Gunning KB, Hanten G, et al. (1991) FVB/N: an inbred mouse strain preferable for transgenic analyses. Proc Nat Acad Sci U S A 88: 2065-2069.

10. Colombo C, Haluzik M, Cutson JJ, Dietz KR, Marcus-Samuels B, et al. (2003) Opposite effects of background genotype on muscle and liver insulin sensitivity of lipoatrophic mice. Role of triglyceride clearance. J Biol Chem 278: 3992 3999.

11. Hadano S, Yoshii Y, Otomo A, Kunita R, Suzuki-Utsunomiya K, et al. (2010) Genetic background and gender effects on gross phenotypes in congenic lines of ALS2/alsin-deficient mice. Neurosci Res 68: 131-136.

12. Menalled L, El-Khodor BF, Patry M, Suárez-Fariñas M, Orenstein SJ, et al (2009) Systematic behavioral evaluation of Huntington's disease transgenic and knock-in mouse models. Neurobiol Dis 35 : 319-336.

13. Ito M, Sugihara K, Asaka T, Toyama T, Yoshihara T, et al. (2012) Glycoprotein hyposialylation gives rise to a nephrotic-like syndrome that is prevented by sialic acid administration in GNE V572L point-mutant mice. PLoS One 7: e29873.

14. Tong Y, Tempel W, Nedyalkova L, Mackenzie F, Park HW (2009) Crystal structure of the $\mathrm{N}$-acetylmannosamine kinase domain of GNE. PLoS One 4 e7165.

15. Valles-Ayoub Y, Saechao C, Haghighatgoo A, Neshat MS, Esfandiarifard S, et al. (2008) Validation of GNE:p.M712T identification by melting curve analysis. Genet Test 12: 101-109.

16. Leroy JG, Seppala R, Huizing M, Dacremont G, De Simpel H, et al. (2001) Dominant inheritance of sialuria, an inborn error of feedback inhibition. Am J Hum Genet 68: 1419-1427.

17. Valles-Ayoub Y, Haghighatgoo A, Saechao C, Khokher Z, Creencia C, et al (2012) Mixed Inbred FVB;B6 Background Strain Attenuates Kidney Disease and Improves Survival of Gnem712t/M712T Mice. Molecular Biology 1:104.

18. Ehrnhoefer DE, Butland SL, Pouladi MA, Hayden MR (2009) Mouse models of Huntington disease: variations on a theme. Dis Model Mech 2: 123-129.

19. Houde C, Banks KG, Coulombe N, Rasper D, Grimm E, et al. (2004) Caspase-7 expanded function and intrinsic expression level underlies strain-specific brain phenotype of caspase-3-null mice. J Neurosci 24: 9977-9984. 